\title{
Ayak ve ayak bileği avasküler nekrozunda tedavi yöntemleri
}

\section{Treatment methods in foot and ankle avascular necrosis}

\author{
Semih Ayanoğlu¹, Ömer Serdar Hakyemez ${ }^{1}$, Yunus İmren² \\ ${ }^{1}$ İstanbul Medipol Üniversitesi Tıp Fakültesi, Ortopedi ve Travmatoloji Anabilim Dalı, İstanbul \\ 2S.B.Ü Okmeydanı E.A.H. Prof. Dr. Cemil Taşçığlu Şehir Hastanesi Ortopedi ve Travmatoloji Anabilim Dalı, İstanbul
}

\begin{abstract}
Ayak ve ayak bileğinin avasküler nekrozu, nadir fakat önemli bir ağrı ve fonksiyonel bozukluk nedenidir. Bu süreç ayak ve ayak bileğindeki herhangi bir kemikte meydana gelebilir; ancak, çoğunlukla sesamoidler, metatars başları, naviküler kemik ve özellikle talus gibi karakteristik kemiklerde ortaya çıkar. Bu lezyonların tedavisinde temel radyografik bulguların anlaşılması önemlidir. Çeşitli görüntüleme yöntemleri ile çalışmalar yapılmışsa da çoğu hastalığın tanısında manyetik rezonans görüntüleme, bu anormalliğin tespiti ve karakterizasyonu için en hassas ve spesifik yöntemdir. Tedavi seçenekleri, takip ve yük vermede kısıtlama gibi konservatif tedavilerden perkütan delme, ayak bileği artrodezi ve total ayak bileği artroplastisi dâhil cerrahi tedaviye kadar uzanmaktadır. Ayak bileği kırıklarında, sekel geliştirme riski yüksek olan hastaları daha iyi tanımlamak, tedaviye ve cerrahiye karar verme sürecine yardımcı olmak için daha fazla araştırmaya ihtiyaç vardır.
\end{abstract}

Anahtar sözcülkler: avasküler nekroz; sesamoid; Freiberg; Müller-Weiss hastalığı; talus; Smillie; Ficat
Avascular necrosis of the foot and ankle is a rare but important cause of pain and functional impairment. This process can occur in any bone in the foot and ankle; however, it mostly occurs in characteristic locations such as sesamoids, metatarsal heads, navicular bone and especially talus. It is important to understand the basic radiographic findings in the treatment of these lesions. Although studies have been conducted with various imaging methods, magnetic resonance imaging is the most sensitive and specific method for the detection and characterization of this abnormality in the diagnosis of most diseases. Treatment options range from conservative treatments such as follow-up and weight-bearing restrictions to surgical treatment including percutaneous piercing, ankle arthrodesis and total ankle arthroplasty. More research is needed to further identify patients at high risk of developing these sequelae of ankle fractures and to assist with treatment and surgical decision-making.

Key words: avascular necrosis; sesamoid; Freiberg; Müller-Weiss disease; talus; Smillie; Ficat

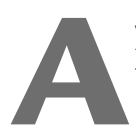
yak ve ayak bileğinin avasküler nekrozu, nadir fakat önemli bir ağrı ve fonksiyonel bozukluk nedenidir. Başlangıç evrelerinde ayak kemik iliği ödemi sendromuyla benzerlikler gösterebilir ve ortalama 6 ay içinde kendiliğinden düzelebilmektedir. Avasküler nekroz, ayak ve ayak bileğindeki herhangi bir kemikte meydana gelebilir; ancak, çoğunlukla sesamoidler, metatars başları, naviküler kemik ve talus gibi karakteristik kemiklerde ortaya çıkar.

\section{SESAMOID AVASKÜLER NEKROZ (AVN)}

Ayak sesamoid kemikleri, fleksör hallusis brevisin (FHB'nin) distal medial ve lateral slipleri içerisinde bulunurlar. Her iki sesamoid, birinci plantar metatarsal arterden beslenirler. Buna ek olarak plantar arktan da beslenme desteği alır. Medial sesamoid daha geniş olup metatars başının hemen altında bulunmaktadır. Bu nedenle medial sesamoide binen yük, laterale binen yüke kıyasla daha fazladır. Medial sesamoide etki eden kuvvetler daha fazla olmasına rağmen hangi sesamoidde AVN prevalansının daha yüksek olduğu kesin değildir. ${ }^{[1]}$

Sesamoid AVN en sık 20-30 yaşlarındaki kadınlarda görülür. Hastalar yük verme veya yürüme evresinin son evresinde 1. metatarsofalangeal (MTF) eklemin plantar yüzeyinde ağrı ile başvururlar. ilk başvuruda ağıı ve ödem için; elevasyon, soğuk uygulama, istirahat ve non-steroid anti-enflamatuvar ilaç kullanımı önerilmelidir. Sesamoidin avasküler nekrozu (AVN), anatomik ve mekanik faktörlerin yanı sıra tekrarlayan mikrotravmanın bir sonucu olarak gelişir. Sesamoid AVN en sık

- Illetişim adresi: Doç. Dr. Semih Ayanoğlu, TEM Avrupa Otoyolu Göztepe Çııışı No: 1, 34214 Bağcılar, İstanbul Tel: 0532 - 3221037 e-posta: semihayanoglu@gmail.com

- Geliș tarihi: 21 Eylül $2020 \quad$ Kabul tarihi: 6 Ekim 2020 
T1 ve T2 sekans manyetik rezonans (MR) görüntülemede düşük sinyal yoğunluğu ile ve geç evre radyografik parçalanma (fragmantasyon) ile teşhis edilir. ${ }^{[1]}$

Sesamoid AVN'nin cerrahi dışı tedavisinde; koruyucu çizme (ROM Walker), alçı veya tabanlık ile ilgili sesamoidin yükten kurtarılması amaçlanmaktadır. Ancak literatürde başarı oranı belirsizdir. Sesamoid AVN'nin cerrahi tedavisinde ilgili sesamoid çıkartılır. Yapılan müdahale, en yaygın olarak tam memnuniyet veya ağrının giderilmesiyle sonuçlanır. Komplikasyonlar arasında halluks varus ve halluks valgusun yanı sıra itme gücü kaybı yer alır. ${ }^{[1]}$

\section{FREIBERG HASTALIĞI}

1914 yllında Dr. Albert H. Freiberg, 2. metatars başının avasküler nekrozunu ilk kez tanımlamıştır. Freiberg hastalığı, ikinci metatars başının osteokondrozu ile karakterizedir, fakat sadece 2. metatars başı ile sınırlı değildir. Primer osteokondrozların en sık görülen dördüncü formudur. ${ }^{[2]}$ Freiberg gibi osteokondroz hastalıkları, eğer erken müdahale edilirse sonunda kendini kısıtlayan ve genellikle cerrahi olmayan yöntemlerle düzelebilen hastalıklardır. ${ }^{[3]} \mathrm{Bu}$ hastalığın nedenleri içerisinde; genellikle travma, ayak biyomekaniğiyle ilgili problemler ile arteriyel yetersizlikleri de içeren çoklu sebepler olduğu düşünülmektedir. Diabetes mellitus, sistemik lupus eritematosus ve hiperkoagülabilite, Freiberg hastalığı için tanımlanmış bazı sistemik risk faktörleridir. Ağrının sinsi ve ilerleyici olması yaygın bir özelliktir. ${ }^{[2]}$

Freiberg hastalığı sıklıkla ikinci metatarsofalangeal eklemi etkiler (\%68) fakat daha az sıklıkla üçüncü (\%27), dördüncü (\%3) ve beşinci $(<\% 2)$ metatarsofalangeal eklemlerde de görülebilir. ${ }^{[4]}$ Fizik muayenede etkilenen eklemde effüzyon ve eklemin hemen plantar/ dorsalinde hassasiyet görülür. MTF eklemin hareket açıklığında azalma, palpe edilebilen krepitasyon ve diğer tarafa kıyasla artmış anterior laksite görülebilir. ${ }^{[2]}$ Son olarak, ileri evre Freiberg hastalığında pençe parmak (claw toe) ya da üst üste binmiş parmak (cross-over toe) deformiteleri görülebilir.

Freiberg hastalığı gibi osteokondroz hastalıklarının erken evrelerinde radyolojik değerlendirme genellikle dikkat çekici değildir. ${ }^{[3]}$ Freiberg hastalığında en erken radyolojik (direkt grafi) belirtiler, semptomların ilk başlangıcından ortalama 3-6 hafta sonra görülür ve eklem aralığında hafif genişleme ile karakterizedir. ${ }^{[5,6]}$ Hastalık ilerledikçe etkilenen metatars başının dorsalinde çökme görülebilir.

MR, hem evrelendirme hem de ameliyat öncesi planlama için büyük bir öneme sahiptir. Freiberg hastalığının erken evrelerinde bulgular direkt grafide bulgular görülmeden önce MR'de kemik iliğinde sinyal artışı şeklinde belli olabilir. ${ }^{[2]}$

\section{Freiberg Hastalığı İçin Smillie Evreleme Sistemi ${ }^{[7]}$ : (Şekil 1)}

Evre 1: İskemik epifizde fissür şeklinde kırık oluşur. Kırık sahasında sklerotik kansellöz kemiğin varlığı ve komşu metafizlerle karşılaştırıldığında epifızde kan akımı olmayışı diğer özellikleridir.

Evre 2: Kansellöz kemiğin absorpsiyonu daha proksimaldedir. Santral kıkırdak başa doğru gömülürken sınırlar ve plantar kıkırdak intakt kalır. Bu süreçle beraber kıkırdak yüzeyde değişim meydana gelir.

Evre 3: Absorpsiyon ilerler, santral kıkırdak daha derine gömülür, plantar kıkırdak sağlam kalır.

Evre 4: Plantar menteşe (hinge) ortaya çıkana kadar santral kısım çökmeye devam eder. Periferik çıkıntılar santral kısma doğru katlanmaya başlar. Normal anatominin restore edilmesi artık mümkün değildir.

Evre 5: Metatars başında düzleşme ve deformite ile birlikte artroz görülür. Metatars kıkırdağının yalnızca plantar kısmı başın orijinal sınırına sahiptir. Loose body'lerin boyutları küçülür, metatarsın şaftı kalınlaşır ve yoğunlaşır.

\section{Cerrahi Dışı Tedavi}

Ön ayak hareketini sınırlayacak beşik tabanlı (rocker bottom) ve sert tabanlı ayakkabı kullanımı, MTF eklemlerdeki basıncı azaltacak şekilde yastıklamayı sağlamak ve ön ayak "rocker" ile sıkışan MTF eklemini rahatlatmak Freiberg hastalığında cerrahi dışı tedavinin temelidir. Steroid enjeksiyonları ile akut enflamasyonu olan eklem rahatlatılabilir fakat kronik bir rahatsızlık durumunda
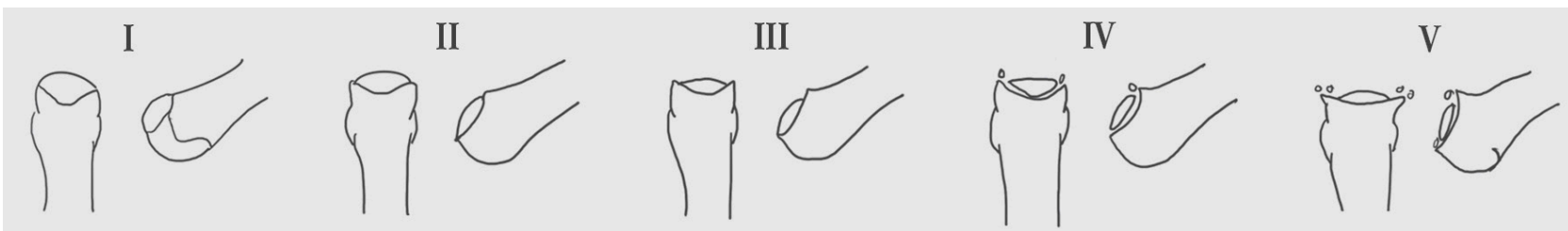

Şekil 1. Smillie evrelemesi. 
işe yaramayacaktır. Trombositten zengin plazma (PRP), kök hücre enjeksiyonu gibi rejeneratif tıp uygulamaları Freiberg hastalığında kıkırdak bozukluğunda etkili olabilir fakat kemik hasarı ve egzostoz durumlarında enjeksiyonlar etkili olmayacaktır. ${ }^{[2]}$

\section{Cerrahi Tedavi}

Cerrahi tedavi, eklem koruyucu ve eklemi rekonstrükte eden uygulamalar olarak ikiye ayrılmaktadır.

Eklem koruyucu cerrahiler arasında debridman, kor dekompresyon, osteotomi ve greftleme işlemleri bulunmaktadır. Eklem debridmanı ilk olarak Freiberg ${ }^{[8]}$ tarafından tariflenmiştir ve başarılı sonuçlara ulaşmıştır. Smillie ${ }^{[7]}$ de kendi orijinal serisinde debridmanın başarısını desteklemiştir. Freiberg hastalığında debridman, belirgin kıkırdak ve kemik defekti gelişmeden ya da eklem için serbest cisimler (loose body) oluşmadan önce meydana gelen kemik kaynaklı sıkışma (impingement) olduğu zaman tercih edilir.

Kor dekompresyon kalçada sıkça kullanılsa da Freiberg hastalığında da kullanıldığını gösteren birkaç olgu sunumu mevcuttur. Bu tedavide amaç avasküler kemikteki artmış intraosseöz basıncı azaltarak metatars başına yeniden kan akımını sağlamak için 1,1 mm'lik Kirschner telleri (K-telleri) ile fenestrasyon yapılır. ${ }^{9,10]}$

Hasarlanmış metatars başındaki kemiğin greftlenmesi ilk olarak 1967'de Smillie ${ }^{[7]}$ tarafından tariflenmiştir. Evre 1 ve 2'de hastalığa temel dekompresyon uygulanırken evre 3'te metatars başının çökmüş olan kısmı redükte edilir ve epifız plağı tekrardan perfore edilir. Metatars başının redüksiyonu sonrası kalan defekt de kansellöz otogreftle doldurulur. Benzer bir teknik 1979'da Lawton [11], daha sonra da Helal ve Gibb [12] tarafından yayımlanmıştır. 2002'de Hayashi ve ark. [13] tarafindan Smillie evre 4 hastalıkta femoral kondilden osteokondral greft nakli (mozaikplasti) tariflenmiştir. Bu hasta tedaviden 1 yıl sonra ağrısız olarak koşmaya ve atletik aktivitelere geri dönmüştür.

Freiberg hastalığında dorsal kapalı kama osteotomileri ya da kısaltıcı osteotomiler tercih edilebilir. Dorsal kapalı kama osteotomisi 1979'da Gauthier ve Elbaz tarafından tariflenmiştir. ${ }^{[4]}$ Kondral hasarın olduğu kısımdan yapılan intra-artiküler osteotomi ile hasarlanmış kıkırdak çıkartılmış ve plantar kıkırdak santrale kaydırılmıştır (Şekil 2). Elli üç olgunın 52 'sinde semptomlarda belirgin iyileşme gözlenmiştir.
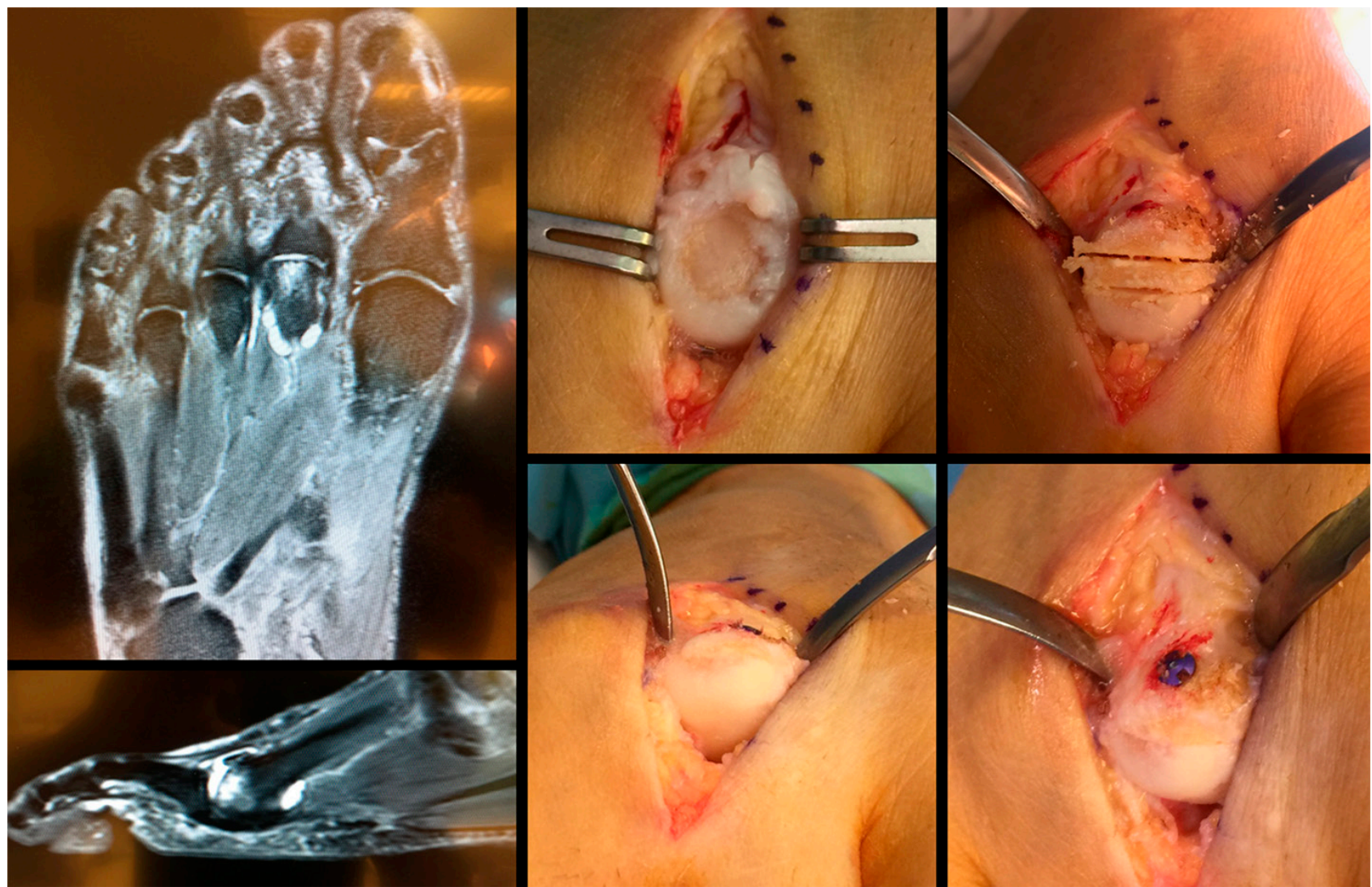

Şekil 2. Freiberg hastalığı: Smillie evre 4. 
Ekstra-artiküler osteotomilerle de kısa ve orta dönemde başarılı sonuçlar elde edilmiştir. Chao ve ark. ${ }^{[14]}, 13$ hasta ile yapılan bir çalışmada ekstra-artiküler dorsal kapalı kama osteotomisi ile \%85'lik başarıya ulaşmıştır. Her ne kadar intra-artiküler bir osteotomi, metatars başının elevasyonundan kaçınarak transvers metatarsaljinin potansiyel riskini azaltsa da osteotominin distalinde az bir kemik dokusu kaldığı için tespit daha zayıftır. Ekstra-artiküler osteotomide distalde yeteri kadar kemik doku kalıp tespit daha sağlam olsa da transvers metatarsaljiden kaçınmak için metatars başını eleve etmemeye dikkat edilmelidir.

Smith ve ark. ${ }^{[15]}$, anormal metatars başını dekomprese etmek için metatars boynu seviyesinden metatars kısaltıcı osteotomi yapmıştır. Osteotomi daha sonra T plak ile sabitlenmiş ve 4,9 yıllık takipte 16 hastadan birisi hariç hepsi sonuçlardan memnun olmuştur.

Eklemi rekonstrükte eden yöntemlerden metatars başı eksizyonunun tarihi önemi vardır. Bu yöntemle transvers metatarsalji riski yüksek olup, parmakta kısalma ve 2. metatars başının eksizyonu durumunda ise halluks valgus deformitesi meydana gelebilmektedir (Şekil 3). ${ }^{[4]}$

İnterpozisyonel doku artroplastisi, ağır dejeneratif MTF değişiklikleri olan Smillie evre 4-5 hastalarda bile başarıyla kullanılmıştır. ${ }^{16]}$ Bu yöntemde, MTF eklem kapsülü, ekstansör dijitorum longus ya da ekstansör dijitorum brevis tendonları ve serbest peroneus longus grefti MTF eklem debridmanından sonra eklem aralığını sağlamak için kullanılmaktadır. ${ }^{[5]}$

Osteokondral distal metatarsal allogreft kullanımı da salvaj durumlarında; osteotomi ve interpozisyonel artroplasti gibi önceki cerrahi işlemlerin başarısız olduğu durumlarda kullanılabilir. Özenli hasta seçimi bu cerrahide önemlidir. Bu prosedür sadece metatarsal taraftan kaynaklı dejeneratif değişikliklerde, ameliyat sonrası beklentinin metatars başı rezeksiyonu ile sağlanamadığı durumlarda kullanıımalıdır. ${ }^{[5]}$

Küçük metatarsları replase eden artroplastiler literatürde kısıtlı bir başarıya sahiptir. Silikon, seramik ve titanyum implantlar tercih edilmekle birlikte bu prosedürde; protezin başarısız olması, gevşemesi, sinovit oluşumu, osteolizis, enfeksiyon ve ameliyat edilen parmağın disfonksiyonu ile metatarsaljiye kadar giden çeşitli komplikasyonlar gösterilmiştir. ${ }^{[5]}$

\section{MÜLLER-WEISS HASTALIĞı (MWH)}

Müller-Weiss (Mueller-Weiss) Hastalığı, naviküler kemiğin fragmantasyon, skleroz ve deformitesi ile karakterize ağrılı bir ayak hastalığıdır. Etkilenmiş olan naviküler kemik karakteristik olarak virgül şeklindedir. Talonaviküler ve naviküloküneiform eklemlerde çeşitli derecelerde artrit görülebilir. ${ }^{[17-19]}$

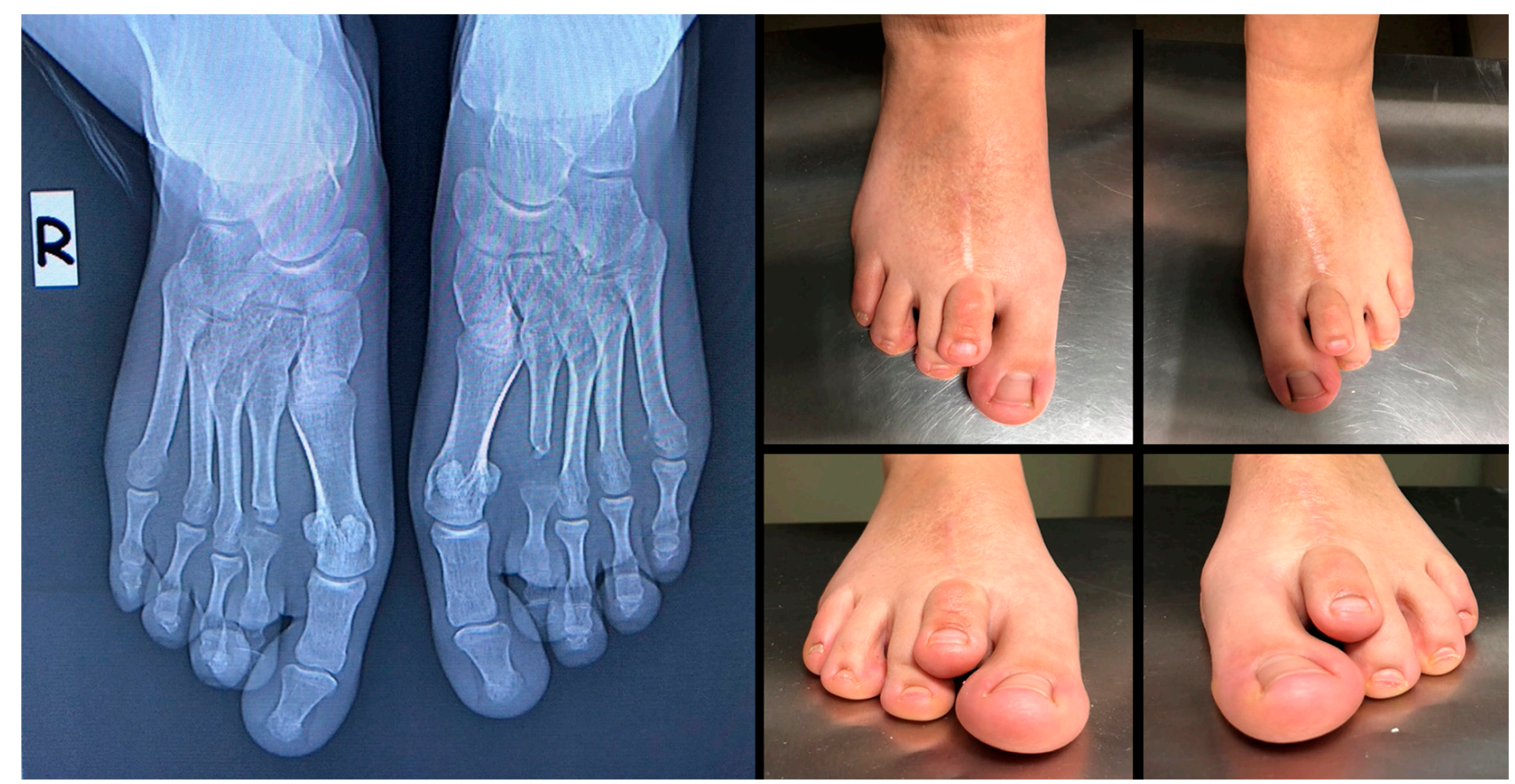

Şekil 3. Freiberg hastalığı: Metatars başı eksizyonu sonrası gelişen transfer metatarsalji ve 2. parmak deformitesi (Ameliyat sonrası 16. yıl). 
Sağlıklı naviküler kemik tipik olarak kayık şeklindedir. Distalde konveks, proksimalde konkav şekilli eklem yüzeyleri mevcuttur. Proksimalde talus başı ile eklemleşirken distalde küneiformlarla, inferolateralde ise küboid ile eklemleşir. Naviküla iki arter tarafından perfüze olur. Dorsalis pedis arteri, naviküler kemiğin dorsalini ve lateral $1 / 3$ 'ünü beslerken medial plantar arter de kemiğin plantar kısmını ve medial kısmının bir bölümünü besler. Navikülanın beslenme paterni sirkümferensiyel olduğu için osseöz kısmın ortasında vasküler beslenmenin bozuk olduğu bir alan mevcuttur. [20]

Navikula, ayağın medial kolonunun kilit taşı olup ayağın medial longitudinal ve transvers arkın bütünlügüne katkı sağlar. ${ }^{[21]}$ Navikulada dorsolateral fragmentasyon ve kollaps olması durumunda orta ayak ve ard ayakta fonksiyonel dizilim bozukluğu ve ilerleyici deformiteler meydana gelebilir. ${ }^{[22,23]}$ Bu hastalığın evrelemesinde Maceira ve Rocheca'nın tariflediği radyolojik evreleme sistemi kullanılmaktadır (Şekil 4). ${ }^{[22]}$

MWH'nin gerçek insidansı tam net olarak bilinmese de sıklıkla bilateral olduğu ve kadınlarda daha sık görüldügü bilinmektedir. ${ }^{[24]}$ Hastalığın tipik prezantasyonu orta ayak ve ard ayak dorsumunda kronik ağrıdır. Hassasiyet genelde dorsomedialdedir. ${ }^{[19,22]}$

Görüntüleme yöntemlerinde naviküler fragmantasyon, ayak deformiteleri ve artritik değişikliklerin varlığı ya da yokluğu değerlendirilmelidir. ${ }^{[25]} \mathrm{MWH}^{\prime}$ 'nin radyolojik ana bulgusu, ayak anterior-posterior grafide navikülanın virgül şeklinde görülmesidir. Lateral grafide de daralma ve skleroz görülür. Yük vererek çekilen lateral grafide artmış kalkaneal eğim açısı, azalmış talokalkaneal açı, ard ayak varusuna bağlı sinus tarsinin geniş görülmesi (see-through sign), anormal cyme çizgisi, çift talar dome gölgesi ve ard ayak ile ayak bileğinin eksternal rotasyonuna bağlı gelişen fibulanın posterior yerleşimi görülür. ${ }^{[26]}$

\section{Cerrahi Dışı Tedavi}

ilk olarak non-steroid anti-enflamatuvar ilaç kullanımı, hasta eğitimi, aktivite modifikasyonu, zayıflama, ayakkabı modifikasyonu, ortez, breys kullanımı ve alçılama gibi cerrahi dışı tedavi denenmesi gerektiği birçok yazar tarafından önerilmiştir. ${ }^{[27]}$ Ayakkabı modifikasyonu, ortez ve breys kullanımında ana amaç orta ayak hareket açıklığını sınırlamak ve topuk kaldırma sırasında talonaviküler ekleme binen yükü azaltmaktır.

\section{Cerrahi Tedavi}

Çoğu yazar cerrahi tedavi gereksinimine deformitenin derecesinden ziyade semptomların ciddiyetine göre karar verilmesi gerektiğini savunmaktadır. Cerrahi tedavide amaç; iyi dizilimle beraber medial kolon yüksekliğini sağlamak ve plantigrad bir ayak elde etmektir. Fakat henüz MWH cerrahisi için bir fikir birliği (konsensus) yoktur.

\section{Evre Radyolojik Tanımlama}

$1 \quad$ Normal düz grafi

Kemik taraması(bone scan)ve MR görüntüleme hastalığı gösterir

2 Talusun navikula üzerinden hafif dorsolateral subluksasyonu M-T çizgisinin dorsal açılanması BT/MR navikulada meydana gelen yapısal hasarın ilk evrelerini gösterir

$3 \quad$ Medial kolon yüksekliğinde kayıp ( talus başı ile medial ve orta küneiformlar arasındaki boşluk) Ark yüksekliği kaybı (lateral görüntülemede artmış taloküboid overlap) Ard ayak varusu M-T dizilimi nötral

4 Medial kolonda artmış çökme ve arkta yükseklik kaybı Ard ayak ekinde M-T çizgileri plantar tarafta kesişir BT'de subtalar eklemde dejenerasyon meydana gelir (özellikle anterior fasette)
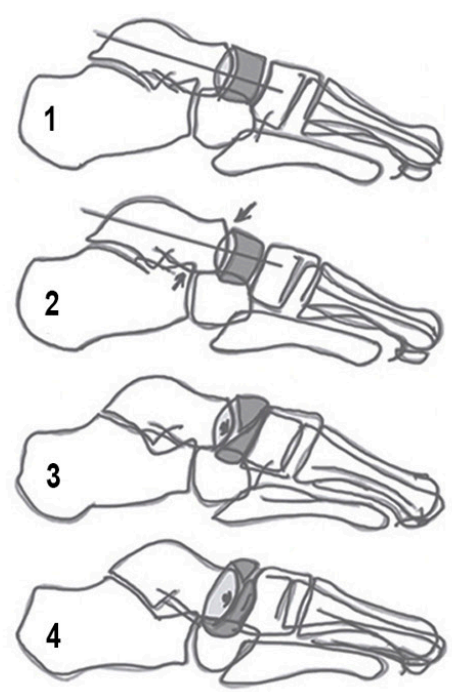

5 Taloküneiform eklem formasyonu oluşumu Navikülanın total ekstrüzyonu

Belirgin/ilerlemiş topuk varusu ve paradoksal totale yakın ark kaybı

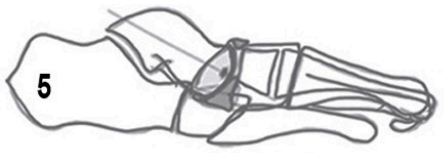

Şekil 4. MWH'de Maceira-Machera radyolojik evrelemesi (BT, bilgisayarlı tomografi; MR, manyetik rezonans; M-T, Meary-Tomeno). 


\section{Artrodez}

MWH'de navikülada ağrı ve perinaviküler artrit olması durumunda artrodez endikedir. Talonaviküler artrodez, talonaviküloküneiform artrodez, double artrodez ve triple artrodez için çeşitli cerrahi teknikler tanımlanmıştır. Eğer belirgin varus dizilim bozukluğu mevcutsa ek bir kalkaneal osteotomi düşünülmelidir. ${ }^{[26,28,29]}$ Allogreft ve otogreft kullanımı ile de başarılı sonuçlar elde edilmiştir. ${ }^{[19]}$ İnternal tespit düşünüldüğü durumlarda kalan kemik stok klinik öneme sahiptir. Evre 4-5 MWH'de yeterli kemik stok olmayacağı için köprü tespit düşünülebilir. Tespitte vida, staple ve/veya plaklar kullanılabilir (Şekil 5). ${ }^{[19]}$

\section{Kalkaneal Osteotomi}

Eklem artrodezinde temel hedef artriti tedavi etmek ve medial arkı yeniden elde etmektir. Fakat MWH'de ağrı sadece eklem dejenerasyonundan değil medial arkın çökmesine ve ard ayak varusuna bağlı meydana gelen bozulmuş ayak bileği biyomekaniği ve ortaya çıkan dengesiz yük dağılımından da kaynaklanmaktadır. Varus deformitesi görüldügüü zaman ard ayak dizilim bozukluğunun cerrahi düzeltilmesi de planlanmalıdır. ${ }^{[18,29]}$

Artrodez ve kalkaneal osteotomiye ek olarak perkütan dekompresyon, nekrotik kemiğin çıkartılması ve iliak kanat kansellöz kemik ile greftleme, debridman
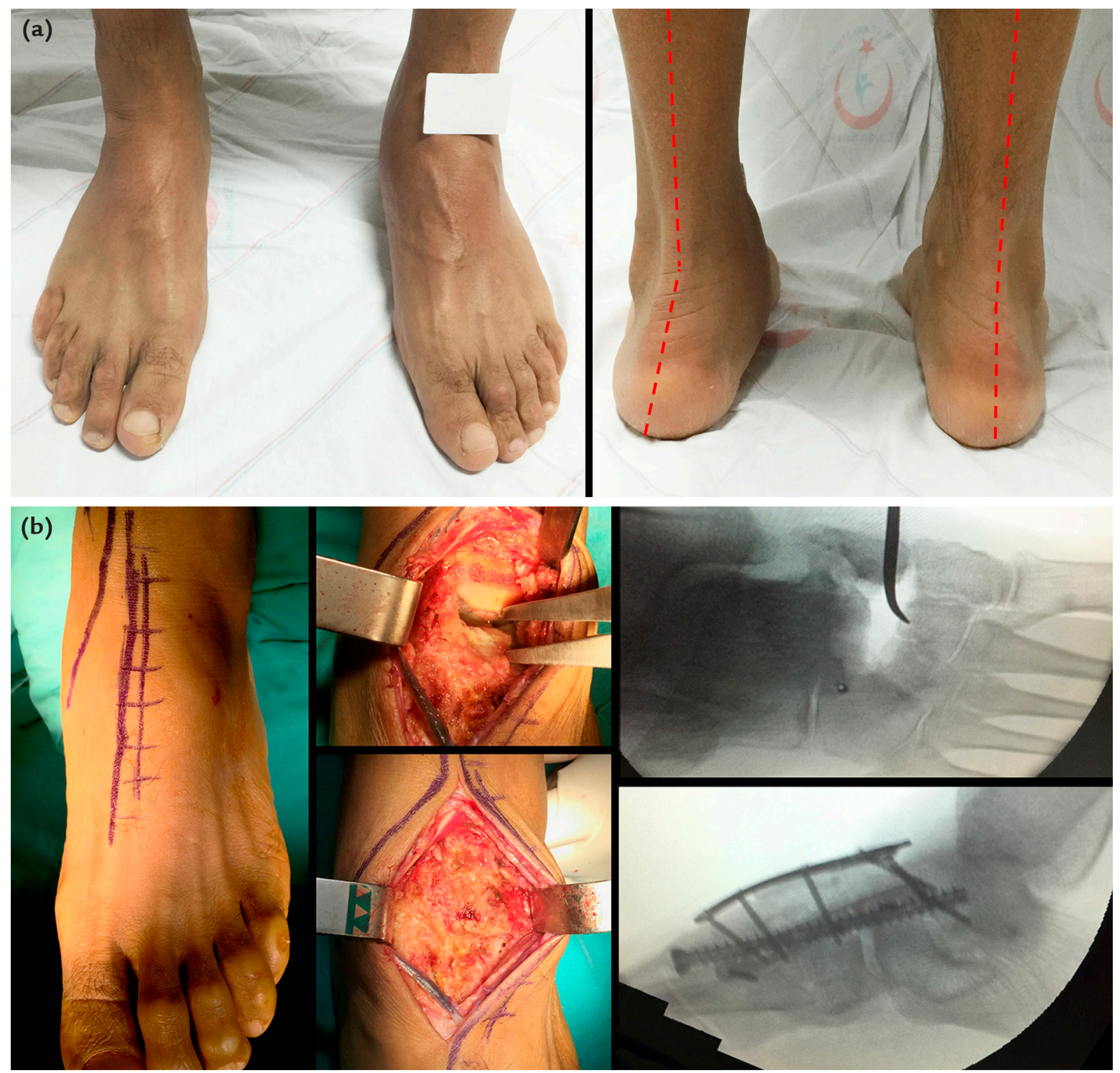

Şekil 5. a, b. Müller-Weiss hastalığı; evre 4. 
ve serbest vaskülarize medial femoral kondil grefti ile greftleme gibi çeşitli tedavi yöntemleri tariflenmiştir. ${ }^{[26]}$

\section{TALUS AVASKÜLER NEKROZU}

Temel semptomları; ağrı, deformite ve ilerlemiş artrite bağlı olarak ayak bileğinde total hareket kaybı ve yürümede bozukluk görülebilir. Talusun avasküler nekrozu olgularının \%75'inde ayak bileğinde travma mevcuttur. ${ }^{[30]}$ Talus boyun kırıkları (Şekil 6), talus AVN'nin en sık sebebidir ve yaralanmanın ciddiyeti arttıkça AVN insidansı da yükselir. Güncel talus AVN oranları, Hawkins tip I'den tip IV'e kadar sırasıyla \%9,8, \%27,4, $\% 53,4$ ve $\% 48,0$ 'dır. ${ }^{[31]}$ Talus AVN'nin diğer nedenleri de kortikosteroid kullanımı, Addison hastalığı, Cushing hastalığı, alkolizm, kronik pankreatit, orak hücreli anemi hastalığı, periferik arter hastalığı, kronik böbrek yetmezliği, sistemik lupus eritamozus ve iyatrojenik cerrahi komplikasyonlardır. ${ }^{[32]}$

Yapılan çalışmalarda, talus boyun kırıklarında kırık sonrası ilk 6-8 saati geçen cerrahi girişimler sonrası talus AVN gelişme ihtimalinin arttığı gösterilmişti fakat gelişen teknoloji ve yeni tespit cihazları ile birlikte talus boyun kırıkları sonrası cerrahiye kadar geçen süre ile avasküler nekroz gelişim riski arasında anlamlı bir bağlantı bulunamamıştır. ${ }^{[33,34]}$ Talus boyun kırıklarından sonra talus AVN gelişiminde kırık sonrası olan deplasmanın uzanımı prediktif değeri en yüksek olan parametredir. ${ }^{[32-35]}$

Penny ve Davis ${ }^{[33]}$, sklerotik ve avasküler talusa yük vererek yürümenin özellikle takip eden süreçte gelişen revaskülarizasyon eğer yavaş olursa talus dome'unda çökme açısından gerçek bir risk oluşturmazken, revaskülarizasyonun hızlı olması durumunda trabeküler kemikte derin yapısal zayıflık gelişip talus dome'unda geniş bir çökme görülür. Fakat talus revaskülarizasyon hızını ve dönemini belirlemek için herhangi bir yöntem yoktur ve yük vermemenin talar çökmeyi engellediği de gösterilememiştir. Bu yüzden AVN gelişim sonrası yük verip vermeme açısında ortak bir fikir birliği bulunmamaktadır. ${ }^{[33]}$ Tedavi yöntemlerinin seçilmesinde Ficat ve Arlet'in modifiye sınıflaması yardımcı olmaktadır (Tablo 1). ${ }^{[36]}$

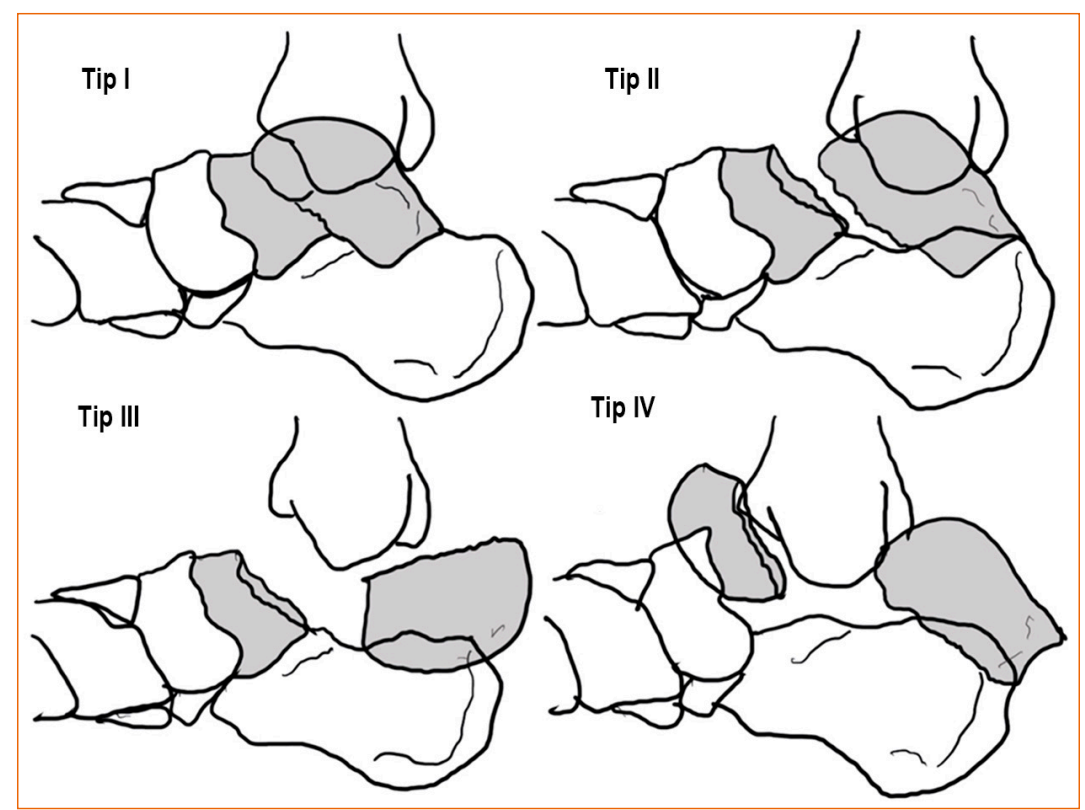

Şekil 6. Talus boyun kırıklarında Hawkins-Canale-Kelly sınıflaması.

Tablo 1. Ayak bileği avasküler nekrozda Ficat-Arlet sınıflaması ${ }^{[36]}$
Evre I Normal
Evre II Kistik ve/veya sklerotik lezyonlar, normal talar sınır, subkondral kırık yok
Evre III Kresent bulgusu ve subkondral kollaps
Evre IV Eklem aralığında daralma, sekonder tibial kistler, osteofitler, artritik değişiklikler 


\section{Kor Dekompresyon}

Erken dönem talus AVN tedavisinde, özellikle nontravmatik etiyolojiye sahip olanlarda, kor dekompresyonun sonuçları oldukça tatmin edicidir. ${ }^{[36-38]}$ Bu yöntemde intraosseöz basınç azaltılır ve nekrotik bölgelerin revaskülarizasyonu hızlanır. Evre 1 ve evre 2 talus AVN'de önerilse de evre 3'ün başında, talus dome'unda belirgin çökme olmadığı durumlarda artrodez veya eklemi feda eden cerrahi yöntemlerden önce de denenmesi yararlı olabilir. Atravmatik AVN'de kor dekompresyonun sonuçları çok iyi olsa da travma sonrası AVN'de kor dekompresyonun sonuçları çalışıımalıdır. ${ }^{[39]}$

\section{Vaskülarize Kemik Grefti}

AVN tedavisinde hem nonvaskülarize hem de vaskülarize kemik greftlerinin kullanımı yararlı sonuçlar vermiştir. Yapısal destek sağlamanın yanında avaskülarize alanın yerine geçip çevre vaskülarize alan ile etkileşerek revaskülarizasyon sürecini hızlandırmaktadır. ${ }^{[39]}$

\section{Parsiyel ve Total Talar Replasman}

Harnroongroj ve ark., ilk olarak talar dome parsiyel talus protezini tanıtmışlardır. 1974 ile 1990 arası ameliyat ettikleri 16 hasta üzerinden yaptıkları çalışmada 9 hasta 11-15 yıl takip edilmiş olup bu hastaların sekizi geçirdikleri ameliyattan memnun kalmış olup sadece biri sorun yaşamıştır. Bu hastada da prostetik stem, talar boyna migre olmuştur. ${ }^{[40]}$

Taniguichi ve ark. da birinci jenerasyon (rezidü talar boyun ve başa bağlanan bir peg ile/sekiz hasta) ve ikinci jenerasyon (peg olmadan/14 hasta) seramik protez ile yaptıkları parsiyel talar replasman ile olan tecrübelerini yayımladılar. Ortalama 98 aylık bir takip sürecinde hastaların 12 'sinden $(\% 54,5)$ iyi ve çok iyi sonuçlar elde ettiklerini ve her iki grupta da AOFAS (The American Orthopaedic Foot and Ankle Society) skorlarında belirgin iyileşme olduğunu söylediler. Her iki gruptan da ikişer hastada komponent gevşemesi, başta ve boyunda kırık olmasına bağlı total talar proteze geçiş gereksinimi oldu. Sonuç olarak da parsiyel yerine total talar protez kullanımının başarısının daha yüksek olduğu yazarlar tarafindan söylenmiş ve total talar protez kullanımı önerilmiştir. ${ }^{[41]}$

Total talus replasmanı ile ilgili en geniş seri Taniguichi ve ark.'nda olup, alumina seramik total talar protezi ile 55 ayak bileğinde yapılan çalışmada başarılı sonuçlar elde etmiş olup bunun talus osteonekrozunda, ayak bileği fonksiyonu devamlılığına yardımı olacak, yararlı bir tedavi olduğunu belirtmişlerdir. ${ }^{[41]}$

\section{Salvaj Prosedürler}

$\mathrm{Bu}$ prosedürler arasında subtalar, talonaviküler, Blair'in tibiotalar artrodezi, tibiokalkaneal (TC) ve tibiotalar (TT) gibi çeşitli artrodez prosedürleri ve parsiyel/total talektomi bulunmaktadır. Başarılı bir füzyondan sonra bu prosedürler hasta için son derece kısıtlayıcı prosedürler olabilmektedir. Yürüyüş anormalliklerine sebep olarak komşu eklemlerde ilerleyici sekonder artrit gelişmesine sebep olabilmektedir. Doğru ayak bileği füzyonu nötral dorsi/plantar fleksiyonda, $0^{\circ}-5^{\circ}$ ard ayak valgusunda ve $5^{\circ}-10^{\circ}$ external rotasyonda talusun tibia ile aynı hatta olduğu pozisyonda yapılmalıdır. ${ }^{[39]}$

Subtalar ve talonaviküler füzyon, çatıda çökme olup semptomların belirgin eklemler ile kısıtlı olduğu durumlarda kullanılmaktadır fakat böyle bir durum nadir görülmektedir. ${ }^{[39]}$

Blair'in tibiotalar füzyonunda talus başı ve boynu, distal tibia anteriordan inferiora kaydırılan korteks ile füzyon elde edilir. Genelde talar cismin çıkartılması ve yapısal greft ile güçlendirme gerekir. Bu füzyonda subtalar hareket kısmı korunurken, kozmetik sonuçlar, ayakkabı kullanımı ve uzvun uzunluğunun korunmasına bağlı sonuçlar daha iyidir. ${ }^{[42]}$

Urquhart ve ark., 11 hasta ile yaptıkları çalışmada uyguladıkları çeşitli ard ayak artrodezi ameliyatlarında semptomatik talus osteonekrozu olan hastalarda 9/11 (\%82) iyi-mükemmel sonuç elde etmiştir. İki hastada enfeksiyona bağlı kaynamama (nonunion) gelişmiştir. Bu çalışma sonucunda talus osteonekrozunda ard ayak artrodezlerinin mükemmel sonuçlara sahip olduğunu göstermiştir. ${ }^{[43]}$ Gross ve ark.'nın yaptığı derlemede, talus AVN için artrodez yapılan altı çalışma incelenmiştir. On bir hastada mükemmel, 10 hastada iyi, üç hastada idare eder ve dört hastada da kötü sonuçlar elde edildiği ifade edilmiştir. Kaynamama insidansı yüksektir (\%18). ${ }^{[44]}$ Yüksek komplikasyon oranı, uzun süreli rehabilitasyon gereksinimi ve artrodez prosedürüyle alakalı uzun dönem morbidite ile ilişkili olarak, özellikle genç hastalarda, hoş olmayan bir nihai tedavi seçeneğidir. ${ }^{[39]}$

Son dönemde giderek artan sıklıkta uygulama firsatı veren çimentosuz total ayak bileği replasmanı için yapılan çalışmalar da oldukça kısıtlı ve sonuçları da çok başarılı değildir. Lee ve ark., çimentosuz total ayak bileği replasmanının revaskülarizasyon tamamlandıktan sonra ve nekrotik kemik tamamen iyileştikten sonra başarılı olma ihtimalinin daha yüksek olduğunu ifade etmişlerdir. ${ }^{[45]}$

\section{KAYNAKLAR}

1. Bartosiak K, McCormick J. Avascular necrosis of the sesamoids. Foot Ankle Clin 2019;24(1):57-67. Crossref

2. Wax A, Leland R. Freiberg disease and avascular necrosis of the metatarsal heads. Foot Ankle Clin 2019;24(1):69-82. Crossref

3. Danger F, Wasyliw C, Varich L. Osteochondroses. Semin Musculoskelet Radiol 2018;22(1):118-24. Crossref 
4. Gauthier G, Elbaz R. Freiberg's infraction: a subchondral bone fatigue fracture. A new surgical treatment. Clin Orthop Relat Res 1979;(142):93-5. Crossref

5. Seybold JD, Zide JR. Treatment of Freiberg disease. Foot Ankle Clin 2018;23(1):157-69. Crossref

6. Hill J, Jimenez AL, Langford JH. Osteochondritis dissecans treated by joint replacement. J Am Podiatr Med Assoc 1979;69(9):556-61. Crossref

7. Smillie IS. Treatment of Freiberg's infraction. Proc R Soc Med 1967;60(1):29-31. Crossref

8. Freiberg $\mathrm{AH}$. Infraction of the second metatarsal bone: a typical injury. Surg Gynecol Obstet 1914;19:191-3.

9. Dolce MO, Osher L, McEneaney P, Prins D. The use of surgical core decompression as treatment for avascular necrosis of the second and third metatarsal heads. Foot 2006;17(3):162-6. Crossref

10. Freiberg AA, Freiberg RA. Core decompression as a novel treatment for early Freiberg's infraction of the second metatarsal head. Orthopedics 1995;18(12):1177-8. https:// pubmed.ncbi.nlm.nih.gov/8749298/

11. Lawton JH. Early surgical intervention for Freiberg's infraction: autogenous epiphysiodesis. J Foot Ankle Surg 1979;18:6871.

12. Helal B, Gibb P. Freiberg's disease: a suggested pattern of management. Foot Ankle 1987;8(2):94-102. Crossref

13. Hayashi K, Ochi M, Uchio Y, Takao M, Kawasaki K, Yamagami $\mathrm{N}$. A new surgical technique for treating bilateral Freiberg disease. Arthroscopy 2002;18(6):660-4. Crossref

14. Chao KH, Lee CH, Lin LC. Surgery for symptomatic Freiberg's disease: extraarticular dorsal closing-wedge osteotomy in 13 patients followed for 2-4 years. Acta Orthop Scand 1999;70(5):483-6. Crossref

15. Smith TW, Stanley D, Rowley DI. Treatment of Freiberg's disease. A new operative technique. J Bone Joint Surg Br 1991;73-B(1):129-30. Crossref

16. Talusan PG, Diaz-Collado PJ, Reach JS. Freiberg's infraction: diagnosis and treatment. Foot Ankle Spec 2014;7(1):52-6. Crossref

17. Kani KK, Mulcahy H, Chew FS. Case 228: Mueller-Weiss disease. Radiology 2016;279(1):317-21. Crossref

18. Li SY, Myerson MS, Monteagudo M, Maceira E. Efficacy of calcaneus osteotomy for treatment of symptomatic MüllerWeiss disease. Foot Ankle Int 2017;38(3):261-9. Crossref

19. Mohiuddin T, Jennison T, Damany D. Müller-Weiss disease: review of current knowledge. Foot Ankle Surg 2014;20(2):7984. Crossref

20. Colles CM, Hickman J. The arterial supply of the navicular bone and its variations in navicular disease. Equine Vet J 1977;9(3):150-4. Crossref

21. Sarrafian SK, Kelikian AS. Syndesmology. In: Kelikian AS, Sarrafian SK, editors. Sarrafian's Anatomy of the Foot and Ankle: Descriptive, Topographic, Functional, 3rd ed. Philadelphia, PA: Lippincott Williams \& Wilkins; 2011. p.163-222.

22. Maceira E, Rochera R. Müller-Weiss disease: clinical and biomechanical features. Foot Ankle Clin 2004;9(1):105-25. Crossref

23. Wang X, Ma X, Zhang C, Huang JZ, Jiang JY. Flatfoot in Müller-Weiss syndrome: a case series. J Med Case Reports 2012;6:228. Crossref

24. Zhang H, Li J, Qiao Y, Yu J, Cheng Y, Liu Y, Gao C, Li J. Open triple fusion versus TNC arthrodesis in the treatment of Mueller-Weiss disease. J Orthop Surg Res 2017;12(1):13. Crossref

25. Welck MJ, Kaplan J, Myerson MS. Müller-Weiss syndrome: radiological features and the role of weightbearing computed tomography scan. Foot Ankle Spec 2016;9(3):245-51. Crossref
26. Ahmed, ASAA, Kandil MI, Tabl EA, Elgazzar AS. Müller-Weiss Disease: A Topical Review. Foot Ankle Int 2019;40(12):144757. Crossref

27. Mayich DJ. The treatment of Mueller-Weiss disease: a systematic approach. Tech Foot Ankle 2016;15(2):59-73. Crossref

28. Chan C, Cheng K, Pan N, Wong KC, Lai HY, Chan HF, Chow HL. Mueller-Weiss syndrome: an important but underrecognised cause of foot pain and deformity. Hong Kong J Radiol 2016;19:57-62. Crossref

29. Fernández de Retana P, Maceira E, Fernández-Valencia JA, Suso S. Arthrodesis of the talonavicular-cuneiform joints in Müller-Weiss disease. Foot Ankle Clin 2004;9(1):65-72. Crossref

30. Metzger MJ, Levin JS, Clancy JT. Talar neck fractures and rates of avascular necrosis. J Foot Ankle Surg 1999;38(2):154-62. Crossref

31. Dodd A Lefaivre KA. Outcomes of talar neck fractures: a systematic review and meta-analysis. J Orthop Trauma 2015;29(5):210-5. Crossref

32. Hermus JP. Osteonecrosis of the talus after talonavicular arthrodesis: a case report and review of the literature. J Foot Ankle Surg 2011;50(3):343-6. Crossref

33. Penny JN, Davis LA. Fractures and fracture-dislocations of the neck of the talus. J Trauma 1980;20(12):1029-37. Crossref

34. Canale ST. Fractures of the neck of the talus. Orthopedics 1990;13(10):1105-15. https://pubmed.ncbi.nlm.nih. gov/2251228/

35. Horst F, Gilbert BJ, Nunley JA. Avascular necrosis of the talus: current treatment options. Foot Ankle Clin 2004;9(4):75773. Crossref

36. Mont MA, Schon LC, Hungerford MW, Hungerford DS. Avascular necrosis of the talus treated by core decompression. J Bone Joint Surg Br 1996;78-B(5):827-30. Crossref

37. Delanois RE, Mont MA, Yoon TR, Mizell M, Hungerford DS. Atraumatic osteonecrosis of the talus. J Bone Joint Surg Am 1998;80(4):529-36. Crossref

38. Marulanda GA, McGrath MS, Ulrich SD, Seyler TM, Delanois RE, Mont MA. Percutaneous drilling for the treatment of atraumatic osteonecrosis of the ankle. J Foot Ankle Surg 2010;49(1):20-4. Crossref

39. Dhillon MS, Rana B, Panda I, Patel S, Kumar P. Management Options in Avascular Necrosis of Talus. Indian J Orthop 2018;52(3):284-96. Crossref

40. Harnroongroj $T$, Vanadurongwan $\mathrm{V}$. The talar body prosthesis. J Bone Joint Surg Am 1997;79(9):1313-22. Crossref

41. Taniguchi A, Takakura $Y$, Tanaka $Y$, Kurokawa $H$, Tomiwa K, Matsuda T, Kumai T, Sugimoto K. An alumina ceramic total talar prosthesis for osteonecrosis of the talus. J Bone Joint Surg Am 2015;97(16):1348-53. Crossref

42. Ross JS, Rush SM, Todd N, Jennings MM. Modified Blair tibiotalar arthrodesis for posttraumatic avascular necrosis of the talus: A case report. J Foot Ankle Surg 2013;52(6):77680. Crossref

43. Urquhart MW, Mont MA, Michelson JD, Krackow KA, Hungerford DS. Osteonecrosis of the talus: Treatment by hindfoot fusion. Foot Ankle Int 1996;17(5):275-82. Crossref

44. Gross CE, Haughom B, Chahal J, Holmes GB. Treatments for avascular necrosis of the talus: A systematic review. Foot Ankle Spec 2014;7(5):387-97. Crossref

45. Lee KB, Cho SG, Jung ST, Kim MS. Total ankle arthroplasty following revascularization of avascular necrosis of the talar body: Two case reports and literature review. Foot Ankle Int 2008;29(8):852-8. Crossref 